\title{
REVIEW
}

\section{The regulation of appetite}

M Druce, S R Bloom

Arch Dis Child 2006;91:183-187. doi: 10.1136/adc.2005.073759

The worsening global obesity epidemic, particularly the increase in childhood obesity, has prompted research into the mechanisms of appetite regulation. Complex pathways modulate energy balance, involving appetite centres in the hypothalamus and brain stem, and hormonal signals of energy status released by the gut and by the periphery. Better understanding of appetite regulation improves understanding of the aetiology of obesity. Manipulation of this homoeostatic system offers potentially useful treatments for obesity.

See end of article for authors' affiliations

......................

Correspondence to:

Prof. S R Bloom,

Department of Metabolic Medicine, Imperial College London, 6th Floor, Commonwealth Building, Hammersmith Hospital, Du Cane Road, London W12 ONN, UK; s.bloom@ imperial.ac.uk

Accepted 14 October 2005

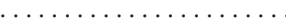

$\mathrm{T}$ he World Health Organisation has classified obesity as an epidemic, and the associated healthcare costs pose a vast financial burden. ${ }^{1}$ Adult definitions of overweight and obesity use body mass index (BMI) cut-off points of 25 and $30 \mathrm{~kg} / \mathrm{m}^{2}$ related to long term adverse outcomes. The prevalence of obesity in adults has increased by over $75 \%$ worldwide since $1980 .^{2}$ In the UK, between 1980 and 2000, the prevalence of obesity rose from $6 \%$ of men and $8 \%$ of women to $21 \%$ and $21.4 \%$ respectively. About $55 \%$ of the adult population is overweight or obese. ${ }^{3}$

\section{EPIDEMIOLOGY OF OBESITY}

The definition of obesity in children is complex as endpoints of mortality and disease are less common. The current definition is based on age and gender specific 85th and 95th centiles of BMI. Around 22 million children under 5 worldwide are obese, ${ }^{4}$ and in the UK the prevalence of childhood obesity rose from $1.2 \%$ in 1984 to $6 \%$ in 2002-03. ${ }^{5}$

Adult obesity increases the risk of type 2 diabetes, hypertension, stroke, cardiovascular disease, respiratory problems, gallbladder disease, osteoarthritis, sleep apnoea, and certain cancers. Over two thirds of children aged 10 and older who are obese will become obese adults, and the rise in medical complications in adults is mirrored in children. One in four overweight children aged 6-12 has impaired glucose tolerance, and $60 \%$ of these children have at least one risk factor for heart disease. ${ }^{4}$ Currently $4 \%$ of all adolescents and 30\% of overweight adolescents in the USA have the metabolic syndrome. ${ }^{6}$

\section{BACKGROUND TO OBESITY}

The increasing prevalence of obesity in developed countries is driven by changes in diet, in particular, the availability of calorie dense, palatable food. In recent decades the prevalence of snacking and soft drink consumption has increased. ${ }^{7}$ Dietary changes have been accompanied by reduced physical activity. Only $22 \%$ of American children meet the recommendations for basic activity levels, and $25 \%$ are classed as completely sedentary. ${ }^{8}$ The combined increase in energy consumption and decrease in expenditure predispose to weight gain.

The effect of the environment on weight gain interacts with a genetic contribution to obesity. In evolutionary terms survival is favoured by a genetic predisposition for fat storage in times of plenty to aid survival in times of famine. ${ }^{9}$ Family, twin, and adoption studies indicate that obesity is highly heritable, with the estimated genetic contribution to BMI ranging from $60 \%$ to $84 \%{ }^{4}$

Identification of polygenic determinants of obesity in the general population is complex. However, significant advances in understanding the appetite regulation system have occurred through the study of individuals with severe obesity inherited in a Mendelian pattern. While these include pleiotropic syndromes such as Bardet-Biedl syndrome, Albright's hereditary osteodystrophy, and fragile $X$, in which the link between defective gene product and regulation of energy balance is unclear, there are also important monogenic disorders discussed later. ${ }^{10}$ The commonest syndromal cause of human obesity is Prader-Willi syndrome, caused by lack of the paternal segment of a section of chromosome 15. The region of the affected chromosome contains several candidate genes, but their role in obesity is not yet defined. One proposed mediator is the gut hormone ghrelin. ${ }^{10}$

\section{APPETITE AND ENERGY HOMOEOSTASIS} A complex physiological system balances energy intake and expenditure, comprising afferent signals and efferent effectors. Hunger leads to initiation of eating. When a meal is ingested, satiety hormones contribute to digestion and a feeling of fullness. Central circuits in the brain integrate satiety signals and signals of long term energy status to produce a coordinated response to the change in nutritional status.

\section{CENTRAL REGULATION}

The nuclei of the hypothalamus (shown in fig 1) and brain stem are important regions for regulation of energy homoeostasis. The arcuate nucleus (ARC) can access signals from the periphery. The signals act on two distinct neuronal populations. One population co-expresses the orexigenic agouti-related peptide (AgRP) and neuropeptide Y (NPY); the other population releases cocaine and amphetamine regulated transcript (CART) 


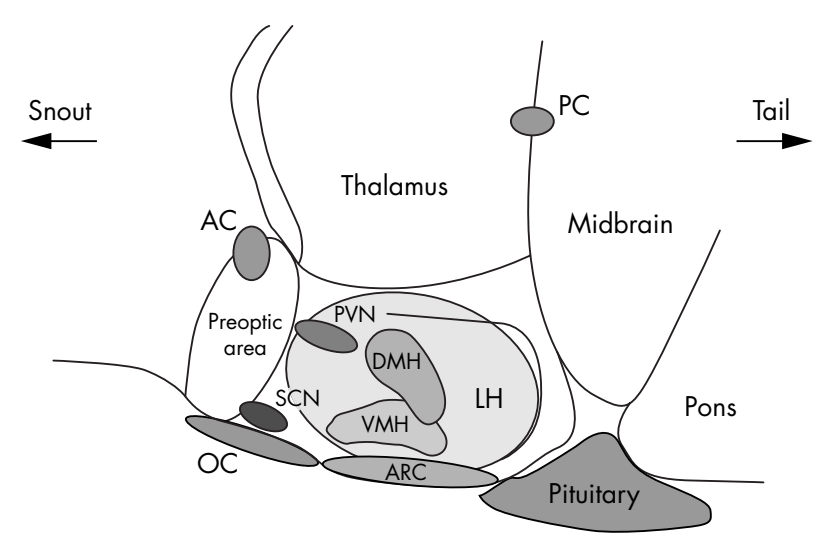

Figure 1 Diagram representing sagittal section through a rodent brain to show the nuclei of the hypothalamus involved in appetite regulation. ARC, arcuate nucleus; VMH, ventromedial nucleus of the hypothalamus; $\mathrm{DMH}$, dorsomedial nucleus of the hypothalamus; LH, lateral hypothalamus; SCN, suprachiasmatic nucleus; OC, optic chiasm; PVN, paraventricular nucleus.

and proopiomelanocortin (POMC), both of which inhibit feeding (fig 2). Both of these populations project to the paraventricular nucleus (PVN) and other nuclei involved in energy regulation. ${ }^{11}$ (However, there may be more than one population of CART neurones in the hypothalamus with different effects on food intake. ${ }^{11}$ )

Defects in neuropeptide appetite circuits can deregulate energy homoeostasis, resulting in obesity. Examples of the effects of dysfunction of appetite regulation can be seen in the melanocortin system. The POMC molecule is the precursor for several cleavage products known as melanocortins. The most important of these in the ARC is alphaMSH which inhibits food intake. Homozygous mutations in the POMC gene cause early onset obesity, adrenal insufficiency, and red hair pigmentation in humans. ${ }^{12}{ }^{13}$ Heterozygous mutations in POMC may cause more subtle defects contributing to inherited obesity. ${ }^{14}$ Obesity can also result when, despite normal POMC transcription and translation, there is a problem with peptide processing, such as congenital deficiency of the processing enzyme prohormone convertase $1 .{ }^{15}{ }^{16}$ The receptors for the POMC cleavage product play a role in energy balance. The MC4 receptor is implicated in as much as $6 \%$ of severe early onset human obesity, ${ }^{17}$ while a particular variant of the receptor is negatively associated with obesity. ${ }^{18}$ MC4 receptor abnormalities result in a distinct obesity syndrome with variable clinical severity. Features include increased ad libitum food intake without deficit in basal energy expenditure, hyperinsulinaemia, and normal puberty and fertility. ${ }^{17}$ MC4R agonists are in development as an obesity therapy. The role of the MC3 receptor is less clear, but mutations of this receptor have also been found in humans with morbid obesity. ${ }^{10}$

Various hypothalamic nuclei other than the ARC also play a role in the control of appetite and body weight. Several neuropeptides are involved, including melanin concentrating hormone $(\mathrm{MCH})$ and the orexins. The brain stem is also important in the control of food intake. ${ }^{11}$ The rewarding nature of food may act as a stimulus to feeding, even in the absence of an energy deficit. The reward circuitry involves interactions between several systems, including opioids, the dopaminergic system, endocannabinoids, and serotonin. ${ }^{19}$ CBl (endocannabinoid) receptor antagonists are in trial in humans and have been shown to reduce appetite and body weight. ${ }^{20}$

\section{PERIPHERAL REGULATION}

\section{Gut hormones}

Hunger and meal initiation

Ghrelin

Ghrelin is synthesised predominantly by the stomach. It is the endogenous ligand for the growth hormone secretagogue receptor which is expressed in brain stem and hypothalamic nuclei including the ARC. ${ }^{21}$

In rodents, ghrelin is a potent stimulus to feeding with the maximum effect observed within an hour of peripheral administration. The resulting plasma levels are comparable to those observed after a 24 hour fast. ${ }^{22}$ Chronic ghrelin administration induces adiposity, ${ }^{22}{ }^{23}$ and CNS injection of anti-ghrelin antibodies inhibits the normal feeding response after fasting. ${ }^{24}$ While early gene expression suggests an action via the $\mathrm{ARC},{ }^{25}$ ghrelin action also requires an intact vagus nerve, with an absence of feeding effects in vagotomised rodents. ${ }^{26}$

Human data support a role for ghrelin in appetite regulation. Plasma levels are high in the fasted state and fall after eating, ${ }^{27}$ and exogenous infusion of ghrelin increased food intake at a buffet meal by $28 \%$ compared with saline control. ${ }^{28}$

A role for ghrelin in the aetiology of human obesity has been proposed. Ghrelin levels are lower in obese subjects compared to lean, and weight loss results in an increase in ghrelin level, which may contribute to difficulties in maintaining the reduced weight. Food fails to suppress ghrelin levels in obese humans, ${ }^{29}$ which again could impair postprandial satiety and contribute to overeating. Indeed

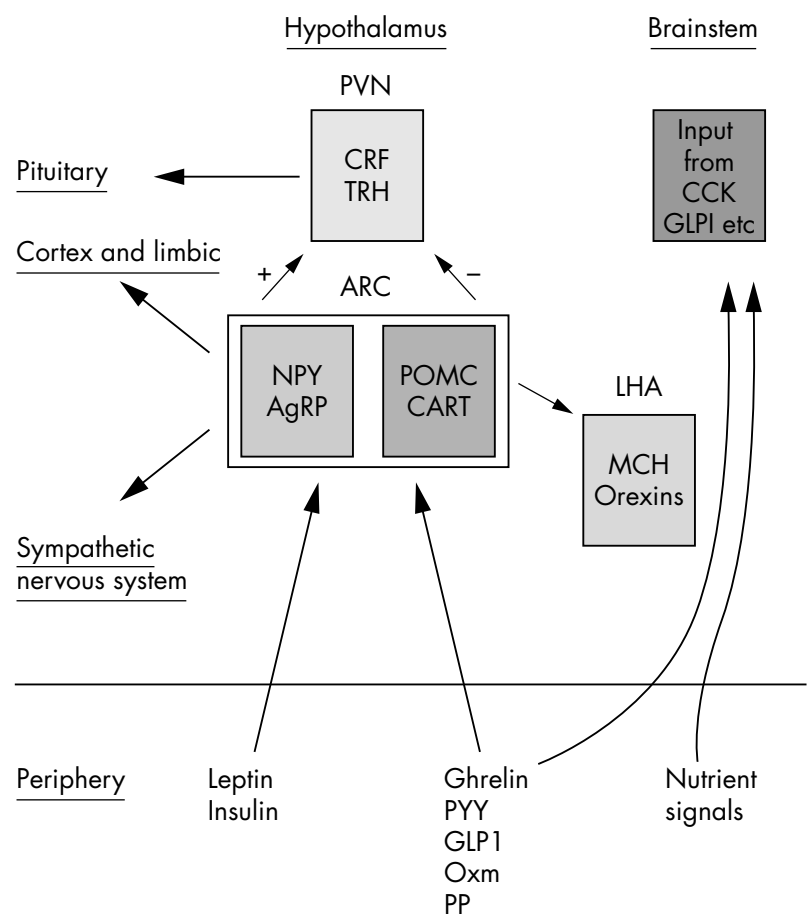

Figure 2 Schematic representation of appetite control-actions of gut hormones and long term adiposity signals on neuronal populations in the arcuate nucleus and the integrated response of anorexigenic and orexigenic populations of neurones in the hypothalamus. ARC, arcuate nucleus; PVN, paraventricular nucleus; LHA, lateral hypothalamic area; $\mathrm{CRF}$, corticotroph releasing factor; TRH, thyrotropin releasing factor (form part of integration with energy expenditure); NPY, neuropeptide Y; AgRP, agouti related peptide; POMC, proopiomelanocortin; CART, cocaine and amphetamine regulated transcript; $\mathrm{MCH}$, melanin concentrating hormone; CCK, cholecystokinin; GLP-1, glucagon-like peptide 1; PYY, peptide YY; Oxm, oxyntomodulin; PP, pancreatic polypeptide. 
individuals with Prader-Willi syndrome have grossly increased ghrelin levels, and this could be a cause of their hyperphagia. ${ }^{11}$ Ghrelin metabolism during fetal development suggests a contribution to programming of mechanisms involved in energy balance. Ghrelin decreases during childhood and adolescence, then in adolescence is proportional to BMI. These findings raise questions regarding the role of ghrelin in growth and development. ${ }^{30}$

\section{Meal termination and satiety factors}

Control of meal size is largely determined by the onset of satiety. This involves messages from mechano- and chemoreceptors from the oral cavity and gastrointestinal tract. In addition, gut peptides (summarised in fig 3) are released in response to a meal. These optimise digestion and signal a change in energy status, with subsequent influence on both physiology and behaviour. Several gut hormones are thought to play a part in the process.

\section{Peptide YY (PYY)}

PYY is produced by the L-cells of the gastrointestinal tract, especially in the distal intestine, and is released into the circulation after meals in proportion to calories ingested. Administration of the active form, PYY 3-36, causes marked inhibition of food intake in rodents and man. ${ }^{31}{ }^{32}$ PYY 3-36 appears to inhibit appetite by acting directly on the Y2 receptor in the ARC - a presynaptic inhibitory autoreceptor. ${ }^{31}$ Although there has been variability in reproducing the anorectic effects of PYY 3-36 in rodents, this may be due to the confounding effects of stress, which can itself reduce food intake via the arcuate nucleus. ${ }^{32}$

Obese subjects have a lower fasting basal PYY and a diminished postprandial rise, but remain sensitive to the inhibitory effects on appetite following exogenous administration. Thus PYY 3-36 might constitute a candidate target for anti-obesity therapy. ${ }^{33}$

\section{Glucagon-like peptide 1 (GLP-1)}

GLP-1 is produced by processing of the proglucagon gene in the gut and brain. The active form of the peptide is GLP-1(736) amide. GLP-1 is released into the circulation after eating in proportion to the amount of food consumed and acts on the pancreas to release insulin. ${ }^{34}$ Secretion may be regulated by sensing the luminal concentration of lipids and carbohydrates-in particular luminal glucose. ${ }^{35}$

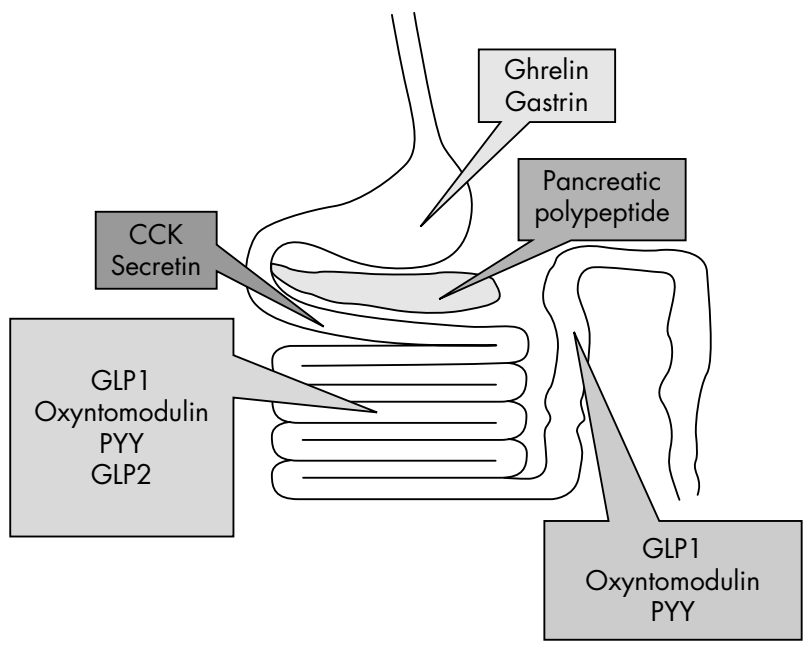

Figure 3 Summary of main gut hormones involved in appetite regulation and their sites of production. CCK, cholecystokinin; PYY, peptide YY; GLP1, glucagon-like peptide 1; GLP2, glucagon-like peptide 2 .
In rodents, peripheral and central administration of GLP1(7-36) inhibits food intake, while administration of the GLP-1 receptor antagonist exendin 9-39 increases food intake. In humans, GLP-1 inhibits food intake in healthy individuals, diabetics, and non-diabetic obese men. ${ }^{11}$

GLP-1 secretion is reduced in obese subjects, and weight loss normalises the levels. ${ }^{36}$ The anorectic effects of GLP-1 are, however, preserved in obesity. ${ }^{37}$ Reduced secretion of GLP-1 could therefore contribute to the pathogenesis of obesity and agonists of the GLP-1 receptor are potential obesity treatments. The therapeutic potential of GLP-1 is limited by its rapid breakdown by dipeptidyl peptidase IV (DPP-IV). However, DPP-IV inhibition may be an effective treatment for type 2 diabetes mellitus and various GLP-1 analogues in development which resist degradation may prove to affect food intake in addition to their effects on insulin. ${ }^{38}$

\section{Oxyntomodulin (Oxm)}

Like GLP-1, Oxm is produced by processing of preproglucagon in the gut and brain, and is released after eating in proportion to nutrient ingestion. ${ }^{39}$ CNS administration of Oxm inhibits food intake in the rat. The anorectic actions are blocked by co-administration of exendin 9-39, suggesting a mechanism of action via the GLP-1 receptor. ${ }^{40}$

Although Oxm is thought to act via the GLP-1 receptor, the sites and mode of action may differ from those of GLP-1. Peripheral administration of Oxm results in activation of the arcuate nucleus (measured via the expression of the early activation gene c-fos). This contrasts with the brain stem activation seen following peripheral GLP-1. When Oxm is administered to rodents intraperitoneally, its effects on food intake can be blocked by administration of the GLPl antagonist exendin 9-39 directly into the ARC. In contrast, arcuate administration of exendin 9-39 does not inhibit the inhibition of food intake caused by GLP-1 administered peripherally. ${ }^{41}$

In humans, intravenous infusion of oxyntomodulin significantly reduced food intake at a free-choice buffet meal. ${ }^{42}$ Chronic administration over a month led to an significant $2.3 \mathrm{~kg}$ reduction in body weight. ${ }^{43}$ While the place of Oxm in physiological weight regulation is not clear, these findings show its therapeutic potential.

\section{Cholecystokinin (CCK)}

CCK is rapidly released from the gastrointestinal tract postprandially. It stimulates gall bladder contraction, pancreatic secretion, and gut motility, and also inhibits food intake via the brain stem in humans and rodents. However, its therapeutic potential is limited by its short half-life. ${ }^{44}$

\section{Pancreatic polypeptide (PP)}

Pancreatic polypeptide is produced in the pancreatic islets and distal gut and released postprandially in proportion to calories ingested. ${ }^{45}$ Evidence from rodents suggests a role for PP in appetite control. ${ }^{46}$ In humans, levels of PP are lower in obese subjects. PP administration reduces food intake in normal weight individuals and in obese subjects with PraderWilli syndrome. Further investigations may indicate potential as a therapy for other obese subjects. ${ }^{11}$

\section{Hormones released by other tissues Insulin}

Several hormones play a role in signalling the overall nutritional status of the body to the brain. The first hormone suggested for this role was insulin. Insulin circulates at levels proportional to fat mass and can cross the blood-brain barrier. Insulin receptors are expressed by brain neurones involved in energy intake. ${ }^{47}$ Insulin within the brain acts as an anorexigenic signal. However, insulin levels are sensitive 
to the acute effects of food ingestion, and its principal physiological function is control of glucose homoeostasis rather than body weight. ${ }^{48}$

\section{Leptin}

The adipocyte hormone leptin is the protein product of the obese $(o b)$ gene. ${ }^{49}$ It is synthesised in white adipose tissue and circulates at concentrations proportional to body fat mass. Food restriction lowers leptin levels, and this is reversed by re-feeding. CNS and peripheral administration of leptin to rodents results in inhibition of food intake and decreased body weight. $^{50}$ Leptin acts on neurones in the ARC to stimulate anorexigenic neurones and to inhibit orexigenic neurones. It is thought that the main function of leptin is to signal starvation when levels are low (conversely high levels signal the levels of body fat stores to the CNS in an environment of nutritional plenty). ${ }^{51}$

The ob/ob mouse is completely leptin deficient, and is hyperphagic, hyperinsulinaemic, and obese. This phenotype can be normalised by the administration of leptin. The $d b / d b$ mouse has a similar phenotype, but in this case is deficient in the leptin receptor and circulating levels of leptin are high. ${ }^{52}$

Human cases of leptin deficiency, identified in at least five families (often consanguineous) have been successfully treated with recombinant leptin. The principal effect of the leptin is reduction in hyperphagia. Leptin is also a permissive factor for pubertal development in humans. A clinical problem in treating leptin deficient individuals has been the development of anti-leptin antibodies-this has so far been overcome by increases in dose of leptin administered. ${ }^{53}$ A family has also been described with mutations in the leptin receptor resulting in obesity. ${ }^{54}$

For the majority of cases of obesity, no causes of receptor dysfunction are found, but circulating levels of leptin are increased in obese humans. Indeed recombinant leptin administered subcutaneously to obese adults results in only a modest effect on body weight. Thus leptin, while pivotal in our understanding of the homoeostatic control of body weight, has failed to live up to its original promise as a therapeutic agent..$^{53}$

\section{Other hormones produced by fat}

Other hormones such as adiponectin and resistin may play a part in energy homoeostasis, affecting appetite, fat distribution, and insulin sensitivity. ${ }^{55}$

\section{TREATMENTS FOR OBESITY}

Strategies available for the management of obesity include appetite inhibition, reduction in nutrient absorption, increase in energy expenditure, and alteration of fat distribution. Many treatments are effective in the short term, but long term efficacy in maintaining weight loss is crucial.

\section{Food intake}

Low calorie diets (800-1500 kcal/day) have variable impact on weight loss. The best macronutrient composition of a diet for weight management is debated. Effectiveness of many of these measures have not been investigated in children. Hypocaloric diets containing less than $20 \mathrm{~g}$ carbohydrate have been used in paediatric patients, but need oversight and monitoring by a physician. ${ }^{4}$

\section{Energy expenditure}

While the largest component of energy expenditure is resting energy expenditure, the most variable component is physical activity, accounting for $20-30 \%$ of the total. ${ }^{56}$ Increasing physical activity is particularly important for maintenance of weight loss in conjunction with dietary changes. ${ }^{4}$

\section{Pharmacology}

Two classes of anti-obesity drug are currently available in the UK. One class inhibits pancreatic lipase and reduces fat absorption. Orlistat (the best known) has several gastrointestinal side effects and is only licensed for use for a period of two years at present. A 54 week clinical trial of orlistat in adolescents found a significantly greater reduction in BMI in patients on orlistat compared to placebo. ${ }^{57}$ The other class of drugs acts centrally to suppress appetite. This group includes sibutramine, use of which is restricted to one year. It has several side effects, particularly tachycardia and hypertension. In a six month trial of sibutramine in adolescents, patients on treatment lost $4.6 \mathrm{~kg}$ more weight than those on placebo. $^{58}$

Weight maintenance is likely to require ongoing therapy, and until more safety and efficacy data are available, use of pharmacological agents in children and adolescents is best limited to clinical trials.

\section{Surgical treatment of obesity}

Three operative procedures are currently in use for surgical treatment of obesity: gastric restriction, gastric bypass, and biliopancreatic diversion. Surgery is usually successful in inducing substantial weight loss in most obese patients, primarily by a necessary reduction in calorie intake. However, there may be an endocrine component to post-surgical weight loss, such as reduction of ghrelin or increase in PYY. ${ }^{59}$ There have been limited reports of experience with bariatric surgery in the paediatric age group, ${ }^{60}$ and the long term sequelae of such procedures at critical stages in development are unknown. Available recommendations suggest limitation to adolescents with a BMI of 40 or more with coexisting obesity associated illness. ${ }^{61}$

\section{FUTURE DIRECTIONS}

The normal homoeostatic mechanisms which operate to tightly regulate the balance between energy intake and energy expenditure break down in obesity, and this may in part reflect the relative deficiency of satiety signals (PYY, GLP1, and PP.) Manipulation of gastrointestinal hormones holds the promise of effective and well tolerated therapies. However for the moment, and specifically with respect to the obesity epidemic in the paediatric population, the first line of management should be prevention. The most effective and safe treatments remain modifications of food intake and increase in energy expenditure. For the future, agents based on gut hormones and which target specific appetite circuits in the brain are awaited.

\section{Authors' affiliations \\ M Druce, S R Bloom, Department of Metabolic Medicine, Imperial College London, 6th Floor, Commonwealth Building, Hammersmith Hospital, Du Cane Road, London W12 ONN, UK \\ Funding: MD is funded by a Wellcome Trust Clinical Research Training Fellowship}

Competing interests: SRB is a Director of Thiakis, a company developing gut hormones as therapeutic agents, and also has shares in the company

\section{REFERENCES}

1 WHO. Obesity: preventing and managing the global epidemic. Report of a WHO consultation on obesity, 1998. Geneva: WHO, 2004.

2 Flegal KM, Carroll MD, Ogden CL, et al. Prevalence and trends in obesity among US adults, 1999-2000. JAMA 2002;288:1723-7.

3 Department of Health. Joint health survey. Health survey for England 2000. London: The Stationery Office, 2001

4 Miller J, Rosenbloom A, Silverstein J. Childhood obesity. J Clin Endocrinol Metab 2004;89:4211-18.

5 Stamatakis E, Primatesta $\mathrm{P}$, Chinn S, et al. Overweight and obesity trends from 1974 to 2003 in English children: what is the role of socio-economic factors? Arch Dis Child 2005;90:999-1004. 
6 Cook S, Weitzman M, Auinger P, et al. Prevalence of a metabolic syndrome phenotype in adolescents: findings from the third National Health and Nutrition Examination Survey, 1988-1994. Arch Pediatr Adolesc Med 2003;157:821-7.

7 St Onge MP, Keller KL, Heymsfield SB. Changes in childhood food consumption patterns: a cause for concern in light of increasing body weights. Am J Clin Nutr 2003;78:1068-73.

8 Burgeson CR, Wechsler H, Brener ND, et al. Physical education and activity: results from the School Health Policies and Programs Study 2000. J Sch Health $2001 ; 71: 279-93$.

9 Schwartz MW, Woods SC, Porte D Jr, et al. Central nervous system control of food intake. Nature 2000;404:661-71.

10 Farooqi IS, O'Rahilly S. Monogenic obesity in humans. Annu Rev Med 2005;56:443-58.

11 Wynne K, Stanley S, McGowan B, et al. Appetite control. J Endocrinol 2005; 184:291-318.

12 Krude H, Biebermann H, Luck W, et al. Severe early-onset obesity, adrenal insufficiency and red hair pigmentation caused by POMC mutations in humans. Nat Genet 1998;19:155-7.

13 Krude H, Biebermann H, Schnabel D, et al. Obesity due to proopiomelanocortin deficiency: three new cases and treatment trials with thyroid hormone and ACTH4-10. J Clin Endocrinol Metab 2003:88:4633-40.

14 Challis BG, Pritchard LE, Creemers JW, et al. A missense mutation disrupting a dibasic prohormone processing site in pro-opiomelanocortin (POMC) increases susceptibility to early-onset obesity through a novel molecular mechanism. Hum Mol Genet 2002;11:1997-2004.

15 Jackson RS, Creemers JW, Ohagi S, et al. Obesity and impaired prohormone processing associated with mutations in the human prohormone convertase 1 gene. Nat Genet 1997; 16:303-6.

16 Jackson RS, Creemers JW, Faroogi IS, et al. Small-intestinal dysfunction accompanies the complex endocrinopathy of human proprotein convertase 1 deficiency. J Clin Invest 2003;112:1550-60.

17 Farooqi IS, Keogh JM, Yeo GS, et al. Clinical spectrum of obesity and mutations in the melanocortin 4 receptor gene. N Engl J Med 2003:348: 1085-95

18 Heid IM, Vollmert C, Hinney A, ef al. Association of the 103I MC4R allele with decreased body mass in 7937 participants of two population based surveys. J Med Genet 2005;42:e21.

19 Saper CB, Chou TC, Elmquist JK. The need to feed: homeostatic and hedonic control of eating. Neuron 2002;36:199-211.

20 Black SC. Cannabinoid receptor antagonists and obesity. Curr Opin Investig Drugs 2004;5:389-94.

21 Kojima M, Hosoda H, Date $Y$, et al. Ghrelin is a growth-hormone-releasing acylated peptide from stomach. Nature 1999;402:656-60

22 Wren AM, Small CJ, Abbott CR, et al. Ghrelin causes hyperphagia and obesity in rats. Diabetes 2001;50:2540-7.

23 Tschop M, Smiley DL, Heiman ML. Ghrelin induces adiposity in rodents. Nature 2000;407:908-13

24 Nakazato $M$, Murakami N, Date $Y$, et al. A role for ghrelin in the central regulation of feeding. Nature 2001;409:194-8.

25 Hewson AK, Tung LY, Connell DW, et al. The rat arcuate nucleus integrates peripheral signals provided by leptin, insulin, and a ghrelin mimetic. Diabetes 2002;51:3412-19.

26 Date Y, Murakami N, Toshinai K, et al. The role of the gastric afferent vagal nerve in ghrelin-induced feeding and growth hormone secretion in rats. Gastroenterology 2002;123:1120-8.

27 Cummings DE, Weigle DS, Frayo RS, et al. Plasma ghrelin levels after dietinduced weight loss or gastric bypass surgery. N Engl J Med 2002;346:1623-30

28 Wren AM, Seal $\sqcup$, Cohen MA, et al. Ghrelin enhances appetite and increases food intake in humans. J Clin Endocrinol Metab 2001;86:5992.

29 English PJ, Ghatei MA, Malik IA, et al. Food fails to suppress ghrelin levels in obese humans. J Clin Endocrinol Metab 2002;87:2984.

30 Chanoine JP. Ghrelin in growth and development. Horm Res 2005:63:129-38

31 Batterham RL, Cowley MA, Small CJ, et al. Gut hormone PYY(3-36) physiologically inhibits food intake. Nature 2002;418:650-4.
32 Halatchev IG, Ellacott KL, Fan W, et al. Peptide YY3-36 inhibits food intake in mice through a melanocortin-4 receptor-independent mechanism. Endocrinology 2004; 145:2585-90.

33 Batterham RL, Cohen MA, Ellis SM, et al. Inhibition of food intake in obese subjects by peptide YY3-36. N Engl J Med 2003;349:941-8.

34 Kreymann B, Williams G, Ghatei MA, et al. Glucagon-like peptide-1 7-36: a physiological incretin in man. Lancet 1987;2:1300-4.

35 Schirra J, Katschinski M, Weidmann C, et al. Gastric emptying and release of incretin hormones after glucose ingestion in humans. J Clin Invest 1996;97:92-103

36 Verdich C, Toubro S, Buemann B, et al. The role of postprandial releases of insulin and incretin hormones in meal-induced satiety-effect of obesity and weight reduction. Int J Obes Relat Metab Disord 2001 ;25:1206-14.

37 Naslund E, King N, Mansten S, et al. Prandial subcutaneous injections of glucagon-like peptide-1 cause weight loss in obese human subjects. Br J Nutr 2004;91:439-46.

38 Ahren B, Schmitz O. GLP-1 receptor agonists and DPP-4 inhibitors in the treatment of type 2 diabetes. Horm Metab Res 2004;36:867-76.

39 Holst JJ. Enteroglucagon. Annu Rev Physiol 1997;59:257-71

40 Dakin CL, Gunn I, Small CJ, et al. Oxyntomodulin inhibits food intake in the rat. Endocrinology 2001;142:4244-50.

41 Dakin CL, Small CJ, Batterham RL, et al. Peripheral oxyntomodulin reduces food intake and body weight gain in rats. Endocrinology 2004;145:2687-95.

42 Cohen MA, Ellis SM, Le Roux CW, et al. Oxyntomodulin suppresses appetite and reduces food intake in humans. J Clin Endocrinol Metab 2003;88:4696-701.

43 Wynne K, Park AJ, Small CJ, et al. Subcutaneous oxyntomodulin reduces body weight in overweight and obese subjects: a double-blind, randomized, controlled trial. Diabetes 2005;54:2390-5.

44 Beglinger C. Overview. Cholecystokinin and eating. Curr Opin Investig Drugs 2002;3:587-8.

45 Adrian TE, Bloom SR, Bryant MG, et al. Distribution and release of human pancreatic polypeptide. Gut 1976;17:940-4.

46 Asakawa A, Inui A, Yuzuriha $H$, et al. Characterization of the effects of pancreatic polypeptide in the regulation of energy balance. Gastroenterology 2003:124:1325-36.

47 Baskin DG, Wilcox BJ, Figlewicz DP, et al. Insulin and insulin-like growth factors in the CNS. Trends Neurosci 1988;11:107-11.

48 Woods SC, Porte D Jr. The role of insulin as a satiety factor in the central nervous system. Adv Metab Disord 1983;10:457-68.

49 Zhang $Y$, Proenca R, Maffei $M$, et al. Positional cloning of the mouse obese gene and its human homologue. Nature 1994;372:425-32.

50 Friedman JM, Halaas JL. Leptin and the regulation of body weight in mammals. Nature 1998;395:763-70.

51 Ahima RS, Prabakaran D, Mantzoros C, et al. Role of leptin in the neuroendocrine response to fasting. Nature 1996;382:250-2.

52 Robinson SW, Dinulescu DM, Cone RD. Genetic models of obesity and energy balance in the mouse. Annu Rev Genet 2000;34:687-745

53 O'Rahilly S, Farooqi IS, Yeo GS, et al. Minireview: human obesity-lessons from monogenic disorders. Endocrinology 2003;144:3757-64.

54 Clement K, Vaisse C, Lahlou N, et al. A mutation in the human leptin receptor gene causes obesity and pituitary dysfunction. Nature 1998;392:398-401.

55 Kadowaki T, Yamauchi T. Adiponectin and adiponectin receptors. Endocr Rev 2005;26:439-51

56 Ravussin E, Bogardus C. Relationship of genetics, age, and physical fitness to daily energy expenditure and fuel utilization. Am J Clin Nutr 1989;49:968-75.

57 Chanoine JP, Hampl S, Jensen C, et al. Effect of orlistat on weight and body composition in obese adolescents: a randomized controlled trial. JAMA 2005;293:2873-83.

58 Berkowitz RI, Wadden TA, Tershakovec AM, et al. Behavior therapy and sibutramine for the treatment of adolescent obesity: a randomized controlled trial. JAMA 2003;289:1805-12.

59 Cummings DE, Overduin J, Foster-Schubert KE. Gastric bypass for obesity: mechanisms of weight loss and diabetes resolution. J Clin Endocrinol Metab 2004;89:2608-15

60 Strauss RS, Bradley $\amalg$, Brolin RE. Gastric bypass surgery in adolescents with morbid obesity. J Pediatr $2001 ; 138: 499-504$

61 Inge TH, Krebs NF, Garcia VF, et al. Bariatric surgery for severely overweight adolescents: concerns and recommendations. Pediatrics 2004;114:217-23. 